Research, part of a Special Feature on Nudging Evolution? Critical Exploration of the Potential and Limitations of the Concept of Institutional Fit for the Study and Adaptive Management of Social-Ecological Systems

\title{
Fit, Interplay, and Scale: A Diagnosis
}

\author{
Arild Vatn $^{l}$ and Paul Vedeld ${ }^{1}$
}

\begin{abstract}
Developing institutions to handle human-environment interactions well is important. In relation to that, the theory of resource regimes, and the themes of fit, interplay, and scale — as originating not least in the work of Oran Young-are core. His work is very impressive. At the same time we observe two sets of issues where we think further development is needed. The first relates to the ontological underpinning of Young's conceptual framework. The second set of issues concerns the definitions of and the relationships between the concepts of fit, interplay, and scale. Regarding the former, we emphasize issues related to "marrying" different theories about human action. Regarding the latter, we note that while the three concepts have a lot of practical appeal, there are still some important challenges surfacing, not least when using them in empirical research. We analyze three challenges: the definitions of the concepts; their internal overlap; and finally, the way environmental regimes are defined and understood as opposed to the wider institutional context of the economy. Our paper offers some direction for how to move forward on the issues specified.
\end{abstract}

Key Words: fit; environmental governance; human action; human-environment interactions; institutions; international environmental agreements; interplay; Oran Young; rational choice; resource regimes; scale; social construction

\section{INTRODUCTION}

Redesigning institutions is a core strategy for improving the governance of environmental resources. Conversely, a high degree of fit between the institutional setting and the biophysical system could reflect a governance structure that performs well over time and is robust in relation to external influence, shocks, and perturbations. Institutions can thus be seen to both cause and solve problems.

Over the last 30 years a rather comprehensive literature on environmental governance and resource regimes has developed. Oran Young is a core scholar in this advancement (e.g., Young 1982, 2002, 2008). This paper is written as a "dialogue" with Young. His work is very impressive, both as to its content and influence. Having tried to use his concepts and perspectives in our own research, we have, however, also encountered some challenges that we want to discuss.

These challenges materialized not least when trying to apply his well-known triad of fit, interplay, and scale. We found the concepts very helpful and at the same time somewhat difficult to apply in a consistent way. Something that seemed to be easily classified as an issue of interplay revealed itself also as a fit issue and vice versa. In trying to disentangle this, we realized that the problem might go deeper than just being about conceptual clarity. It also seemed to uncover some problems with the wider theory building.

In relation to the above, we note that Young $(2002,2008)$ emphasizes that fit, interplay, and scale are "analytic themes". This implies that we may be asking for conceptual stringency to an extent that Young has never intended. Noting this, we also observe that the concepts are widely used, not least in empirical research. Facilitating comparisons and accumulation of knowledge demands conceptual precision. Hence, we find it necessary to clarify the problems we observe in order to support a process toward such clarity.

This paper consists of three main sections. First we offer a brief presentation of the main elements of Young's conceptual framework. Second, we evaluate its ontological and epistemological basis. Third, we use insights from these sections in a discussion of a set of issues related to using the fit, interplay, and scale triad. We close by offering some ideas on how to take this work further.

\section{A BRIEF PRESENTATION OF THE CORE ELEMENTS IN YOUNG'S POSITION}

\section{Young's institutional approach}

In his work-e.g., Young (2002) and Young (2008)—Young draws on what he denotes "new institutionalism". He emphasizes that new institutionalism encompasses a variety of analytic strands, and notes that researchers working with environmental issues have assembled around two of these strands, i.e., "collective action" and "social practice" models. While the first is based on standard rational choice, the latter follows a social constructivist understanding which emphasizes, for example, the role of culture/norms in explaining human action. He also refers to a third perspective coming out of his work and that of his colleagues, "the knowledge action perspective". The latter approach stresses agency, individual leadership, and the role of governance systems in the "way environmental problems are understood" (Young 2008:8).

The core institutional concept in Young's research program is that of resource regimes ${ }^{[1]}$. He sees these as "issue-specific 
institutional arrangements" (Young 2008:15), such as the global climate regime, regional fisheries regimes, or local forest regimes. We note that he does not seem to include the more basic institutions of the economy-e.g., existing property regimes and norms governing present resource use -in the regime concept itself. Hence, the general institutional landscape into which the issue-specific institutional arrangements are placed is not part of the resource regime. The concept of a "governance system" may be understood to also encompass this wider set of institutions (e.g., Young et al. 2008:xxi, Young 2008:14-15). At the same time, Young tends to use "resource regimes" and "governance systems" as synonyms (e.g., Young 2008:26-27).

The emphasis on issue-specific institutional arrangements may be understood by reference to the history of the research program. It was from the outset focused very much on specific environmental agreements, not least of which are international treaties. Hence, resource regimes became the institutions added to handle problems concerning the management of resources and treatment of pollution. This may next reflect the observation that institutions defining access to resources (for example, property regimes like private property, common property, etc.) and those governing the distribution of the products produced on the basis of these resources-e.g., markets-were typically developed first. Next, when environmental problems caused by resource use following from these institutional structures were observed, issuespecific institutional arrangements were developed in attempt to correct the problems. As we discuss later, the divide between resource regimes as issue-specific and "other institutions" may cause some challenges.

\section{Three research foci}

In Young's research program, three research foci-causality, performance, and design-are emphasized. To get an understanding of the broader ideas of the program, we will offer a brief overview of some of the core issues as emphasized in his writings. It should be noted that we are generally in agreement with his position concerning these issues.

\section{Causality}

According to Young (2008:17) "[t]he question of causality concerns the extent to which institutions influence the course of human affairs in a variety of social settings." He further makes a distinction between institutions operating as proximate and as underlying forces and that the "institutions often form elements of interactive causal clusters in contrast to the mainstream conception of causal chains" (Young 2008:10). These complex clusters form composite drivers. Young discusses further the distinction between output, outcomes, and impacts, and states that demonstrating causality at the level of outputs is "a relatively easy task" (Young 2008:18) while "[d]emonstrating the influence of institutions in terms of impacts, by contrast, is extremely hard" (Young 2008:19).
Effects of institutions are often nonlinear and associated with thresholds. In relation to this, Young talks about complex causality referring to both biophysical and socioeconomic forces, and as these interact, it becomes demanding to make an assessment of the contribution of an individual factor. So research in this area "often calls for a high order of sophistication in the analysis of causal clusters rather than the application of reductionist procedures designed to tease out the significance of individual factors" (Young 2008:20-21).

\section{Performance}

In analyzing institutional performance, criteria such as efficiency, equity, robustness, and sustainability are highlighted (Young 2008:21). This implies looking at both stated and unstated goals, comparing relative merits of different regimes, looking into trade-offs between goals, and evaluating changes over time, based on baseline criteria, changing circumstances, and continuous mapping/monitoring and evaluations. A challenge in such performance assessments relates to the fact that there is no alternative existing regime to compare with, and assessing a range from no regime to some kind of "optimal regime" seems difficult or maybe even speculative. Another challenge, according to Young, concerns what is to be assessed-i.e., performance as outputs, outcomes, or impacts.

\section{Design}

Young (2008:24) states that there is a "hope that we can exercise some control over human destiny by crafting the provisions of resource and environmental regimes and adjusting key provisions of existing regimes in order to improve their performance in the light of experience." He states one should not look for "design principles" or universal generalizations, but rather accept the fact that institutional complexities and also factors other than institutions interact with each other. One should be focused on institutional diagnostics, and as much on processes as on outcomes.

Such diagnostics would then "seek to probe the nature of the problem, the overarching political setting, the character of the actors or players, and the prevailing practices" (Young et al. 2008:xv) which would involve a complete resource regime assessment. At the other end, one would also need to assess the feasibility of institutional design; i.e., what is sociopolitically acceptable concerning design, process, and outcome.

Young emphasizes the distinction between intended and nonintended institutions or regimes. Institutional change can be intentional or it can occur as a result of what he (with reference to Hayek) refers to as spontaneous or self-generating regimes (Young 2008:24). Issues of (mis)fit, scale (insensitivity), and (nonfunctional) interplay can thus be results both of intentional and nonintentional processes of regime creation. Intentionally created regimes often reflect negotiated and agreed-upon outcomes, and where misfit or 
Table 1. Misfit between ecosystem dynamics and governance systems.

\begin{tabular}{|c|c|}
\hline Types of misfit & Definition, mechanisms, and examples \\
\hline Spatial & $\begin{array}{l}\text { - Institutional jurisdiction is too small or too large to cover the area extent subject to the institution (lack of wildlife corridor } \\
\text { protection between protected areas for migrating animals [Newmark 1993]). } \\
\text { - Institutional jurisdiction unable to cope with actors or drivers external or internal and important for maintaining the ecosystem(s) } \\
\text { or processes affected by the institution; institutional arrangements can be too large when providing centrally defined blueprints } \\
\text { that ignore existing local biophysical circumstances (Scott 1995) (centrally defined rules for how JFM in Zambia should be locally } \\
\text { designed—one size does not fit all). }\end{array}$ \\
\hline Temporal & $\begin{array}{l}\text { - Institutions formed too early or too late to cause desired ecosystems effect(s) (Lake Turkana fisheries project, built fish treatment } \\
\text { plant demanding continuous inputs of fish while water/fisheries disappear/fluctuate substantially [Watson et al. 1985]). } \\
\text { - Institution (and possibly the actor interaction it entails) produces decisions that assume a shorter or longer time span than those } \\
\text { embedded in the biophysical system(s) affected; and/or social response is too fast, too slow, too short, or too long compared to the } \\
\text { time taken for biophysical processes involved (the speed of invasive species is higher than institutional responses to stop the } \\
\text { expansion [Perrings 2010]). }\end{array}$ \\
\hline $\begin{array}{l}\text { Threshold } \\
\text { behavior }\end{array}$ & $\begin{array}{l}\text { - Institutions may lead to, not recognize, or be unable to avoid abrupt shift(s) in biophysical systems. (Example: if a policy focuses } \\
\text { on "optimal management" of one fish species, then the overall system of interacting species can easily collapse (Edwards et al. } \\
\text { 2004).) } \\
\text { - Institutions provide for inadequate response to contingencies (e.g., lack of rules for action in extreme conditions) or reduces } \\
\text { variation in biophysical systems (e.g., by removing response diversity, whole functional groups of species, or trophic levels, or by } \\
\text { adding anthropogenic stress such as pollution). Institutions fail to respond adequately or at all to disturbances that could have been } \\
\text { buffered or helped to revitalize the system before. Leads to practically irreversible biophysical shifts (monoculture production- } \\
\text { loss of other ecosystem services [Daily 1997]). }\end{array}$ \\
\hline $\begin{array}{l}\text { Cascading } \\
\text { effects }\end{array}$ & $\begin{array}{l}\text { - Institution is unable to buffer or trigger further effects among biophysical and/or social and economic systems (climate anomaly } \\
\text { shifts rainfall between regions; arid regions get much rain, others get less than normal; adaptation problems (Collier et al. 2008). } \\
\text { - Institutional response is misdirected, nonexistent, inadequate, or wrongly timed so as to propagate or allow the propagation of } \\
\text { biophysical changes that entail further causative changes along temporal and or spatial scales (abrupt shifts in soil humidity in } \\
\text { Australia lead to salination and to substantial effects on socioeconomic systems [Pittock 2003]). }\end{array}$ \\
\hline
\end{tabular}

Source: based on Galaz et al. (2008)

scale or interplay failures can impact upon regime efficiency and design. Also intentionally created misfits can appear where powerful actors see this as serving their own interests.

\section{Three core challenges in constructing resource regimes: fit, interplay, and scale}

Moving then to the fit-interplay-scale triad, we note that Young (2008) sees it as a set of analytical themes specific to resource regimes and used to explore issues related to institutional causality, design, and performance. Below we present some of his main ideas as a precursor to our later discussions.

\section{Fit}

"The problem of fit is a matter of the match or congruence between biophysical systems and governance systems" (Young 2008:26). Fit then becomes core to regime building and adaptation. Moreover, with the growing role of anthropogenic influence in biophysical systems, fit becomes increasingly important (Young 2008:27).

In relation to this, contextuality is central. Hence, an institutional arrangement with excellent match for one resource may be a failure for another. Assuming a highly resilient resource can lead to disaster if the resource proves not to be as resilient as expected. The less homogenous the resources are, the more challenges there are. The same is the case if they are vulnerable to extinction and causes are both local and global. Young (2008:xvi) recommends the following:

- Carry out case-by-case assessments of both biophysical and socioeconomic diversity.

- Study the "results of promotion of multilevel governance" because it "does not always produce an enhanced fit between ecosystem dynamics and governance in environmental regimes".

- Study the "quality of interaction among institutional players" in how actors learn, plan together, bridge goals, etc., and how "polycentric institutions are used to ensure political, legal, and financial support for the sustained existence of the institutional framework".

The literature in this field typically distinguishes between spatial, temporal, and functional (mis)fit (e.g., Folke et al. 2007, Young 2008, Paavola et al. 2009). In line with this Galaz et al. (2008) have identified types of misfit (Table 1), substituting functional misfit with "threshold behavior" and "cascading effects". 


\section{Interplay}

Interplay is the perception that "discrete regimes can interact with one another and that such interactions become both more common and significant as the number of discrete governance systems grows in any given social setting" (Young 2008:26). Furthermore, "interplay occurs when the operation of one set of institutional arrangements affects the results of another or others" (Young et al. 2008:xvi). Problems of institutional interplay occur because individual institutional arrangements do not consider impacts on related arrangements especially in relation to performance. These interplays are increasing in society at all levels of interaction.

Young makes a distinction between horizontal and vertical interplay, and between what he calls functional and political (intentional) interplay. Horizontal interplay concerns interplay at the same level of social organization (functionally separated regimes). Vertical interplay appears between different levels of social organization: international, regional, national, and local levels (Table 2).

Table 2. Types of institutional interplay.

\begin{tabular}{lll}
\hline \hline & $\begin{array}{l}\text { Functional } \\
\text { interdependence }\end{array}$ & $\begin{array}{l}\text { Intentional politics of design and } \\
\text { management }\end{array}$ \\
\hline Horizontal & $\begin{array}{l}\text { United Nations } \\
\text { Framework Convention } \\
\text { on Climate Change } \\
\text { (UNFCCC), ozone } \\
\text { regimes }\end{array}$ & $\begin{array}{l}\text { Joint funding mechanisms (e.g., } \\
\text { Global Environment Fund (GEF)) }\end{array}$ \\
Vertical & $\begin{array}{l}\text { Convention on } \\
\text { Biological Diversity } \\
\text { (CBD), national forest } \\
\text { regimes }\end{array}$ & $\begin{array}{l}\text { Convention on Long-Range } \\
\text { Transboundary Air Pollution } \\
\text { (CLRTAP), national air pollution } \\
\text { regimes }\end{array}$ \\
\hline
\end{tabular}

Source: Young (2002)

The interplay between regimes is further seen as a result of either functional interdependencies such as ecological relations (ozone depletion and climate change) or social relations. It can also be institutionally created interdependencies formed by political design and management. Hence, actors may forge links between issues and institutions to reach particular goals, such as nesting arrangements.

Often actors devise packages or clusters of institutional arrangements, largely for strategic purposes rather than as instruments for coming to terms with functional interdependencies (Young 2008:25-26). An example could be that transboundary management regimes are suggested for underlying strategic reasons rather than for (the more obvious) ecological reasons (see J. Petursson, P. Vedeld, and A. Vatn unpublished manuscript).

Scale

Scale is "the extent to which institutional arrangements are similar and exhibit comparable processes across levels of social organizations ranging from the local to the global" (Young 2008:26). Two important reasons for analyzing scale are the incidence of vertical interplay, and the wish to analyze governance systems at different levels of social organization. There is a stress on "the transferability of knowledge regarding institutions from one level of social organization to another" (Young 2008:33).

Young emphasizes that moving from the local to higher levels of organization may involve moves from: homogenous to more heterogeneous institutions, few to many institutions and regimes, and individual influence to system decisions, and, overall, from simple to complex systems (of interplay). $\mathrm{He}$ differentiates between occurrence of scale in time and space, e.g., Young (2002). Concerning spatial scale he emphasizes important differences between local, national, and international policies and institutions. Core issues concern whether we can scale up and down and still see similarities in both design and in how systems perform. Young perceives no intrinsic "optimal level" or entry point of socio-political organization from which to address a challenge. Levels are addressed through political framing that again impacts on how one perceives the problem, accrues causality, suggests solutions, and evaluates the outcomes.

\section{EVALUATING THE ONTOLOGICAL AND EPISTEMOLOGICAL FOUNDATIONS}

Already in his 1982 book, Young emphasized the role of institutions in analyzing environmental and resource use problems. In his book from 2002, he describes his approach more explicitly as institutional while referring to authors as different as Olson (1965), March and Olsen (1989), North (1990), Ostrom (1990), Powell and DiMaggio (1991), Rutherford (1994), and Scott (1995). Interestingly he talks about a lack of a core direction in the field of study and argues that this is because there is an "inability or unwillingness on the part of researchers concerned with the institutional dimensions of environmental change to adopt uniform definitions of central concepts, to specify key variables in a fully compatible manner, and make use of harmonized data sets in evaluating major hypotheses" (Young 2002:xxii).

This is an important observation. The solution to the problems, he argues, is to strike a balance between "the development of a common structure and identification and a preservation of personal niches that appeal to individual researchers" (Young 2002:xii). Referring to the collective action, social practice, and his own knowledge action perspective, Young (2008:8) goes further stating that "[a] hallmark of our research program is an effort to marry - or at least deploy in tandem- the three perspectives . . . . He sees the different institutional perspectives to be complimentary rather than alternative. He notes that " $[\mathrm{w}] \mathrm{e}$ are not in the position at this point to merge the three perspectives fully to create a single overarching theory of environmental institutions. But researchers studying 
these institutions regularly make use of all three perspectives, often in efforts to explain the success or failure of specific institutional arrangements" (Young 2008:8).

We find this approach problematic. The different perspectives Young refers to are based on incompatible assumptions about human action as well as about the relation between action and institutions. They reflect distinct ontological positions that are in logical conflicts (see Vedeld 1994, Vedeld and Krogh 2005). Given this, to simply "marry" the three perspectives is not possible. To allow full freedom of movement between them becomes equally problematic as one can then (almost) always ensure "fit" when explaining each single case. The plan to marry also produces challenges at other levels because the content of concepts like fit, scale, and interplay will thus have different meaning and produce different results.

An alternative understanding, inspired by Kuhn (1970), is to see knowledge generated under different disciplinary matrices to be of different kinds and that any joint use will require careful processes of translation and integration (Knorr-Cetina 1981, Bernstein 1983, Klein 1996, Boden 1999, Bruun 2002, Lattuca 2002). Bernstein (1983) notes that we can nevertheless compare disciplines and the results they produce in different ways. We can recognize losses and gains moving between different understandings. Moreover, "[w]e can even see how some of our standards for comparing them conflict with each other. We can recognize, especially in cases of incommensurability in science, that our arguments and counter-arguments in support of rival paradigms may not be conclusive. We can appreciate how much skill, art, and imagination are required to do justice to what is distinctive about different ways of practicing science and how "in some areas" scientists "see different things" (Bernstein 1983:92-92).

In relation to the above, we want to make three arguments to clarify our position. First, development of a consistent theoretical frame, including insights from different theoretical positions, is possible, but the frame must be based on a common and consistently defined ontological basis. As will be discussed later, the different theories of human action can actually be combined in a certain way, but that demands the specification of a shared ontological foundation. Whether such a basis is acceptable to the various disciplines and researchers involved is another issue.

Second, we certainly do not argue against multidisciplinary research in the sense that researchers with different-i.e., incompatible-disciplinary perspectives work in parallel on issues related to institutions, resource regimes, and, more specifically, on fit, interplay, and scale. That can be very valuable and generate more informed knowledge about various issues. We do, however, believe in the necessity of clarifying one's own ontological and epistemological positions. We think this is crucial in order to establish a basis for creating cumulative learning in the field of regime analyses.

Finally, if more integration of perspectives and knowledge developments is an ambition, recent research on interdisciplinarity and how to address the fact that various bodies of knowledge approach the same issues differently could lend a hand (Knorr-Cetina 1981, Klein 1996, Boden 1999, Bruun 2002, Lattuca 2002, Bernstein 1983). One could use these tools to analyze challenges in relation to the fitinterplay-scale field, asking about where perspectives are compatible and where they are not. Where do we find room for dialogue, translation, and integration? In relation to this, we note that to the extent that natural and social sciences look at different parts of the human-nature nexus, it seems rather straightforward to combine knowledge even with different ontological bases. The most demanding issues are faced within the social sciences.

The core message is that one thus needs to address issues of disciplinary plurality in a scientific and consistent way; i.e., where major challenges are clarified and where the research community in question makes itself more aware of choice of platform and its implications (Klein 1996). In our case, this is of particular interest for the three core concepts of fit, interplay, and scale.

\section{FIT, INTERPLAY, AND SCALE}

The concepts of fit, interplay, and scale are quite attractive because they offer reasonable labels for aspects of regime analyses that have confronted most research practitioners in the field. As an example, "fit" offers associations to a hand and a glove. ${ }^{[2]}$ Certainly, it is a core issue to ensure that the regime fits the dynamics of the resources. Similarly, different regimes may be influencing the same area or the same actors. Hence, their interplay is of utmost importance.

While acknowledging all the good "services" that the concepts seem to offer in relation to institutional causality, design, and performance, we also have encountered several problems when trying to utilize the triad. Some of them might be handled by refining the definitions and maybe by adding other concepts. Some might not be possible to solve in that way. As discussed above, the structure of metaphors as defined may actually reflect ontologies or a mix of ontologies that are problematic.

\section{The issue of fit}

The "hand-glove" metaphor demands first of all that "the hand"-i.e., the biophysical system — can be understood as being independent of "the glove"-the resource regime. Certainly, there are many examples of regimes not fitting the ecosystems involved such that the fit issue can be understood in fairly straightforward ways. Fisheries' regulation is a typical example, where regimes over and over again have failed to produce the aims of the regulations due to the specific 
biophysical complexities encountered (e.g., threshold misfit; see Finlayson and McCay [2000]). Certainly, by increasing our understanding of the dynamics and complexities of the various ecosystems, one would expect that the expanded knowledge base would make it possible to construct regimes that are better fitted/designed.

Ecologists are concentrating much effort on developing such insights, e.g., Folke et al. (2005, 2007), Galaz et al. (2008). This is very important work. The challenge from a governance perspective is, however, not only about how to construct regimes that fit the dynamics and complexities of the resources or ecosystems. No governance structure can be evaluated without reference to an aim. Ecosystems are not fixed entities. They convey many properties and these can, at least to some extent, be re-arranged or modified to change the "delivery" of the system. Hence, the goals we try to attain will influence what we emphasize and see as problems. Forests can be turned into agricultural land. This creates new dynamics, and what is a good fit will likewise be altered. Regime formulations are dominantly related to human use in some sense. Hence, the concept of fit needs to include references to what aspects and capacities of the biophysical system that humans emphasize. It will rarely be about the "pure" biophysical system. Rather, it may be that the "glove can also form the hand". While knowledge of resource dynamics is core, there is hence a very strong normative element involved when defining fit.

The fit concept, as used, tends to underplay the role of actor perspectives in another important way. This concerns the way human action is typically included in the fit literature. No regime can fit a resource-independent of what the aim isif the regime is unable to create the actions wanted or needed. Hence, the fit is not only about "fitting" ecosystem dynamics, our priorities concerning these, and what rules "fit" these issues. It is also about motivations and human interaction. Therefore a theory about fit demands a theory about human motivation and choice (see also D. DeCaro and M. Stokes unpublished manuscript).

As we have already seen, Young takes an eclectic stand at this point. While open-mindedness is generally a merit, we note that in this case it makes the analysis of fit unspecified in a very important sense. Certainly, the collective choice and social practice models are based on very different ontological assumptions. The first is based on the idea that humans maximize individual utility and act strategically in situations where choices are interdependent. The second bases its understanding on action as formed by social practices and that habits and norms of appropriate behavior are core in understanding human action. These models will produce different diagnoses of appearing problems and advise different institutional changes to handle them. They will see "fit" differently.
A possible way forward here lies in the observation that human motivation is itself dependent upon the institutions or regimes (Hodgson 2007; Vatn 2005, 2009a). While some regimes or institutional structures legitimize or accept people who act on the basis of their own interests only, other structures facilitate or expect cooperative will and social engagement, for example. What is appropriate varies across social contexts or regimes. We enter here a field of research that is not very well developed. Instead of "going around" the problem by picking between competing models as may "fit", we as a research community should put much more emphasis into disentangling this interdependency when studying fit issues. The environmental regimes literature would gain from developing a firmer foundation concerning the interdependencies between institutions and human action. A way forward here will be discussed in the closing section of the paper.

In applying Young's concept of fit, we have also encountered challenges concerning the relationships between the specific regime and the institutions governing the use of the resource that are already in place at the time of the establishment of a new regime. Because no regime will enter an institution-free domain, the question arises: how well does the resource regime, which is understood to be the new or specific institutions, fit those institutions already in place? Existing property rights, and norms concerning resource use and what is appropriate to do among present resource appropriators, will influence how well a regime fits through its own effects on behavior. As already emphasized, where the regime is established, a series of social-ecological systems are already in place and, as described by anthropologists, the landscape of institutions is best understood as institutional bricolage (Cleaver 1999).

Young certainly acknowledges this (e.g., Young 2003). The challenge is conceptual. What is a fit issue and what is not? One could reserve the concept of fit for the relationship between the new (single) resource regime as defined and the biophysical system only. Then, however, a separate concept is needed for the fit between the existing institutions and the new or specific ones (see Paavola et al. 2009). ${ }^{[3]}$ Finally, a concept is needed for how the combined set of institutions, that is, the various resource regimes in Young's sense plus all the other institutions that affect relevant action, fit the resources. Such a conceptual development would help to avoid confusion.

As we understand Young, he uses fit mainly in the first meaning (single regime), but sometimes also according to the last (sum of all regimes). The issue of fit between institutions/ regimes could be captured by the term interplay. However, as we have seen, he defines that concept more narrowly, i.e., as between resource regimes. 


\section{What then about interplay?}

Moving to the issue of interplay, the main distinction in Young's analyses goes between the horizontal and vertical dimensions. Problems concerning horizontal interplay appear because regimes operate as functionally split jurisdictions in a world where these functions are physically linked on the ground. One example would be the relation between the Montreal Protocol and the climate regime, where the solution to the ozone problem regulated by the Protocol created increased emissions of greenhouse gases, and this weakened the latter regime. Other examples concern national management of wildlife resources that live in cross-border habitats.

In cases like the above, it is difficult to distinguish between interplay and fit because it is the interplay, i.e., the sum of the regimes, that next results in misfit. One way of avoiding this conceptual problem could be to define fit as an issue only for each issue-specific regime but not the cluster of regimes. It would, however, be rather irrelevant and quite difficult to operate with such a definition. As already emphasized, we are facing "interactive causal clusters". In such a situation it is both difficult and not especially meaningful to try to measure effects of single regimes. As already emphasized, no regime operates independently of existing institutions, whether or not it is a resource regime in Young's terminology. Hence, even in the case of a single resource regime, "misfit" may appear because of dysfunctional interactions with these other institutions. So, do we term this a problem of fit or one of interplay? At the end of the previous section, we emphasized that some see this as a fit issue.

Moving to vertical interplay, we once more note that the concept has practical appeal. However, it is again difficult to differentiate vertical interplay clearly from fit. Certainly, when the topic is different levels of the same issue-specific arrangement, such as the climate regime, the interactions between the various levels of that regime-global, national, local-are evident and crucial to understand. The core question for Young is how well different responsibilities are distributed along the chain from the global agreement through to the national level and to the local level.

However, the reason why one has constructed a system of levels in designing regimes like the one on climate, is because the causal effects of actions taken locally spreads beyond national borders, for example, and in this case become truly global. Hence, it is a characteristic of the biophysical system, together with the structure of nation states, that creates the need for establishing such a designed, layered structure of the regime. If some levels of this regime do not perform well, it could either be because the interaction between levels is not good, or it could be because the distribution of responsibilities across the chain from the local to the global does not fit the dynamics of the resource well. Fisheries management is full of examples of this, where problems across levels of jurisdiction-i.e., local, national, regional, global-to a large extent are caused not least by the fact that the politically dominant level, i.e., the nation states, are badly fitted to managing a resource that moves across their borders. The problem of ill-functioning vertical interplay seems, even in this case, to boil down to one of fit.

The standard definition of interplay directs the focus toward interaction between resource regimes. This is one reasonable way of classification. It ensures emphasis on important issues like how the United Nations Framework Convention on Climate Change (UNFCCC), the Convention on Biological Diversity (CBD), the Montreal Protocol on Substances that Deplete the Ozone Layer, the United Nations Convention of the Law of the Sea (UNCLOS), regional fisheries regimes, and national forest and air pollution regimes interact, etc. However, the resource regimes in Young's sense are installed mainly because existing institutions do not serve stated aims well. A fundamental problem, then, is why these present institutions fail. This question tends to become underemphasized given the way the concepts of fit and interplay are defined. The main reason why environmental problems appear may relate fundamentally to the fact that present institutions separate decision making among agents using the same or interdependent environmental resources (Hagedorn 2008; Vatn 2008, 2009b). It may be argued that the main challenge concerns not the interplay between the environmental regimes, but rather the dynamics of present property rights, markets, and public institutions that exhibit weak "fit" with the biophysical systems involved. Certainly, the "issue-specific" World Trade Organization's trade regime is included in the analyses when found relevant. The basic institutions creating the rights of and interactions between economic and political agents are, however, pushed too far into the background. This easily leads to underemphasizing core power relations and of economic and socio-cultural conflicts of importance for the institutional analysis.

Young asks if institutions really matter given that the performance and effects of environmental regimes are often very weak. In our view - and we believe also in Young'sthis does not reflect the weakness of institutions as a general phenomenon. Rather it demonstrates the weakness of resource regimes (as defined) compared to the strengths of the institutions governing economic activities more generally. This raises the question of whether successful environmental policies or regimes demand changes that go deeper into the structures of our economies. Again, we may call this something else than interplay, but it must be included in the structure of core concepts when studying institutions and environmental change. The present way that concepts such as resource regime, fit, and interplay are defined may constrain the understanding of why problems appear and how they can be handled. 
It is the sum of institutions that influences human action. Hence, it is the relative position of the "signals" sent from various institutional structures - as perceived by the actorsthat shapes the final impacts. Understanding this "sum of motivations" is demanding. Here we note that the different institutional structures may support different types of motivations. This aspect is not well captured in the literature on interplay because agents are typically assumed to have uniform motivations across regimes. As we see it, the dynamics of interplaying regimes may be heavily influenced by the various and competing appeals they have to acting "individually rational" vs. "ecologically responsible". The final incentives and norms that direct the action may be quite different from any linear sum of signals from each regime, assuming that they are all interpreted by a single motivational structure such as utility maximization. What becomes the dominant form of motivation in an area, and how other motivational structures may shape this main configuration, are the core aspects for analysis.

\section{A brief note on scale}

The scale dimension could be included to handle the above issues of vertical interplay. Problem complexes that appear differently at different levels of scale produce special challenges for obtaining institutional fit. They demand scaledesigned or scale-adapted institutional structures.

Young does not pursue that avenue. As we have seen, his focus is on the effect of scaling up and down, asking to what extent one can then transfer knowledge across levels of jurisdiction or social organization. This aspect of scale is also important. Young (2008) emphasizes that scaling in this sense has been an issue that natural scientists have emphasized much more than social scientists.

We have found no explicit argument concerning why Young has chosen to link scale to knowledge; there are many other relevant aspects of scale that could form a basis for a definition. We get the impression that it is more because "scaling knowledge" is a concern of quite some practical importance, than because it is a necessary development to ensure that the conceptual triad becomes a coherent set of variables for institutional analyses of environmental problems. If it is possible to scale up and down, knowledge production becomes a much simpler task. The practical relevance and value of research efforts increase a lot. It leaves, however, one quite significant wall open in the total structure of concepts; i.e., how scale-dependent variation in various phenomena are or should be captured by regime design and development.

At the same time, by linking the concept of scale so strongly to knowledge, Young avoids potential overlap with the concept of vertical interplay, specifically the aspect of the politics of design and management. One issue could certainly be that agents may want to frame issues in such a way as to make them suitable for consideration at different levels of social organization, and whether they are addressed at one level or the other often makes a difference in terms of the interests of key actors. Such issues are in our mind not about knowledge per se, but about power games in the domain of vertical interplay. We note that Young (2008) includes these aspects in his discussions under a section on scale. While being very important issues, we note that this illustrates the problem of consistent application of the triad.

\section{WHERE TO GO FROM HERE?}

Based on the above, we want to conclude by specifying two research agendas that we find important to pursue further. The first relates to the ontological and epistemological bases for research on environmental regimes. The second concerns further development of the fit-interplay-scale conceptualization.

Young is deliberatively open or eclectic concerning the understanding of human action. This may refer to the fact that different cases reveal different types of behaviors and motivational structures. We also believe that it reflects that when working in an interdisciplinary field like the environmental, one is immediately confronted with the potentially incompatible perspectives of different disciplines. This seems to be a much more difficult issue in the interfaces between the various social sciences than across the border between social and natural sciences. It is hence no surprise that we observe both conflict and eclecticism in the literature on the very point of human action.

Noticing that action varies across resource regimes should prompt the question "Why?". As already emphasized, opening up for free movements between explanations or asking for a marriage are both problematic strategies. A way forward could be to ask why different types of regimes, or more generally different types of institutions, make people act so differently. A solution could therefore be found in further development of institutional theory with a specific emphasis on how institutions influence motivations. Maybe people act according to plural motivations - note the distinction between individual vs. social rationality (Vatn 2009a)-and institutions play a crucial role in forming or activating what type of motivation will dominate.

The above actually points toward a "marriage", but it does so in a way that avoids ontological inconsistency. The basic ontological position taken is that not only institutions, but also human motivation, are socially constructed. This position departs from rational choice/collective action theory concerning the assumption of autonomous individuals. Rather, the emphasis is on social construction of human perceptions, preferences, and motivation. At the same time, it does not deny the existence of strategic action. The hypothesis is that while certain institutional structures typically facilitate cooperative action, others facilitate or accept strategic behavior. Deeper insights into these relationships could make the development of regime theory more explicit on the agent- 
structure relations and offer actors engaged in regime development the opportunity to be more reflective on the dynamics of human agency. We do not expect this to result in a complete convergence of the social sciences underpinning regime analyses. We do think, however, that a clearer understanding of these relationships will create a more engaged debate that can generate increased insights across, but also within, positions.

Concerning the fit-interplay-scale triad, we have observed two core issues. First, it is a problem that the triad as defined and the analyses they motivate tend to downplay the role of the general (nonspecific) institutions of our economies. Second, we have observed that the concepts themselves are overlapping. In the introduction we emphasized that maybe it has not been Young's aim to create a common, mutually exclusive, or coherent set of variables. Nevertheless, the conceptual landscape, as it now stands, creates problems to the extent we want to use it to ensure analytical coherence across cases and study areas.

Concerning the first issue, enlarging the research program to also include the "nonspecific" institutions to the core of the program seems both warranted and feasible. Certainly, it expands the institutional landscapes that must be covered, but there are no fundamental theoretical or conceptual problems involved. Such a development would, however, demand a reconsideration of the concept of a resource regime. One alternative here could be to redefine it to include the institutional structures governing use of resources in the production of goods and services more generally (see for example Vatn 2011). There are certainly other ways to go about this.

Concerning the issue of coherence, we observe that the three concepts are used differently across the literature. The lack of coherent use seems to follow from the observation that several issues under interplay and scale can also be formulated as fit problems. We have not been able to establish from where the various concepts and definitions have originated. Maybe, they have been introduced "along the way" as the program has encountered new issues. If so, the problems may reflect an orientation towards "workability" rather than coherence. We think, however, that workability and coherence are not competing aims. To make progress here, we think a conceptual framework that includes the core variables influencing fit, interplay, and scale issues is needed.

Following Young, core sets of variables for such a framework would be institutions, actors, and physical environments/ resources. While seemingly simple, we also observe that institutions, actors, and environments are of different types, and are related to different issues, different levels of organization, etc. In our view, a framework based on these three groups of core variables may be developed to embody the complexity needed to give more precise meaning to fit, interplay, and scale. A solution seems to lie in defining the concepts on the basis of the relationships between variables of such a framework as can be defined at different levels. In relation to this we are reminded that the basic institutions of a society should be offered as much emphasis as the specific environmental regimes. We finally note that we should either go for a more narrowly defined "fit" concept-i.e., a purely structure-oriented concept-or we should redefine fit to become an overarching concept of the relationships between institutions and the biophysical systems that make interplay and scale into specific aspects of the then more-encompassing concept of fit. We believe the latter is the more promising avenue.

Responses to this article can be read online at: http://www.ecologyandsociety.org/issues/responses. php/5022

\section{Acknowledgments:}

The authors would like to thank Katharine Farrell and Andreas Thiel for ideas they presented at the Roundtable on the Ecological Economics of Fit at the 11th biennial conference of The International Society for Ecological Economics, in Bremen-Oldenburg, August, 2010. Their presentation was a great inspiration and support for us in developing the ideas conveyed in this paper. We also thank two anonymous reviewers for insightful comments. The standard disclaimers apply.

\section{LITERATURE CITED}

Bernstein, R. 1983. Beyond objectivism and relativism, sciences, hermeneutics and praxis. Basil Blackwell, London, UK. http://dx.doi.org/10.2307/2214991

Boden, M. 1999. What is interdisciplinarity? Pages 13-24 in R. Cunningham, editor. Interdisciplinarity and the organisation of knowledge in Europe. European Commission, Brussels, Belgium.

Bruun, H. 2002. Epistemic encounters: intra- and interdisciplinary analyses of human action, planning practices and technological change. Humanecologiska Skrifter 18. Human Ecology Section, Department for Interdisciplinary Studies of the Human Condition, Göteborg University, Göteborg, Sweden.

Cleaver, F. 1999. Reinventing institutions: bricolage and the social embeddedness of natural resource management. The European Journal of Development Research 14(2):11-30. http://dx.doi.org/10.1080/714000425 
Collier, P., G. Conway, and T. Venables. 2008. Climate change and Africa. Oxford Review of Economic Policy 24(2):337-353. http://dx.doi.org/10.1093/oxrep/grn019

Daily, G. C., editor. 1997. Nature's services: societal dependence on natural ecosystems. Island Press, Washington, D.C., USA. http://dx.doi.org/10.1130/0016-7606(1946)57 [707:NOTA]2.0.CO;2

Edwards, S. F., S. L. Jason, and B. P. Rountree. 2003. Portfolio management of wild fish stocks. Ecological Economics 49:317-329. http://dx.doi.org/10.1016/j.ecolecon.2004.04.002

Finlayson, A. C., and B. J. McCay. 2000. Crossing the threshold of ecosystem resilience: the commercial extinction of northern cod. Pages 311-333 in F. Berkes and C. Folke, editors. Linking social and ecological systems: management practices and social mechanisms for building resilience. Cambridge University Press, Cambridge, UK.

Folke, C., T. Hahn, P. Olsson, and J. Norberg. 2005. Adaptive governance of social-ecological systems. Annual Review of Environmental Resources 30:441-73 http://dx.doi.org/10.1146/ annurev.energy.30.050504.144511

Folke, C., L. Pritchard, Jr., F. Berkes, J. Colding, and U. Svedin. 2007. The problem of fit between ecosystems and institutions: ten years later. Ecology and Society 12(1):30. [online] URL: http://www.ecologyandsociety.org/vol12/iss1/ $\underline{\operatorname{art} 30 / .}$.

Galaz, V., P. Olsson, T. Hahn, C. Folke, and U. Svedin. 2008. The problem of fit among biophysical systems and resource regimes, and broader governance systems: insights and emerging challenges. Pages 147-186 in O. R. Young, L. A. King and $\mathrm{H}$. Schroeder, editors. Institutions and environmental change: principal findings, applications, and research frontiers. MIT Press, Cambridge, Massachusetts, USA.

Hagedorn, K. 2008. Particular requirements for institutional analysis in nature-related sectors. European Review of Agricultural Economics 35(3):357-384.

Hodgson, G. M. 2007. The revival of Veblenian institutional economics. Journal of Economic Issues XLI(2):325-340.

Knorr-Cetina, K. 1981. The manufacture of knowledge: an essay on the constructivist and contextual nature of science. Pergamont Press, Oxford, UK.

Klein, J. T. 1996. Crossing boundaries, knowledge, disciplinarities, and interdisciplinarities. University Press of Virginia, Charlottesville, Virginia, USA.

Kuhn, T. S. 1970. The structure of scientific revolutions. Third edition. University of Chicago Press, Chicago, Illinois, USA.
Lattuca, L. R. 2002. Learning Interdisciplinarity: sociocultural perspectives on academic work. The Journal of Higher Education 73(6):711-739.

March, J. G., and J. P. Olsen. 1989. Rediscovering institutions: the organizational basis of politics. Free Press, New York, New York, USA.

Newmark, W. D. 1993. The role and design of wildlife corridors with examples from Tanzania Ambio 22 (8):500-504.

North, D. 1990. Institutions, institutional change and economic performance. Cambridge University Press, Cambridge, UK. http://dx.doi.org/10.1017/CBO9780511808678

Olson, M. 1965. The logic of collective action. Harvard University Press, Cambridge, Massachusetts, USA.

Ostrom, E. 1990. Governing the commons: the evolution of for collective action. Cambridge University Press, Cambridge, UK.

Paavola, J., A. Gouldson, and T. Kluvánková-Oravská. 2009. Interplay of actors, scales, frameworks and regimes in the governance of biodiversity. Environmental Policy and Governance 19:148-158. http://dx.doi.org/10.1002/eet.505

Perrings, C., H. Mooney, and M. Williamson, editors. 2010. Bioinvasions and globalization: ecology, economics, management, and policy. Oxford University Press, Oxford, UK.

Pittock, B., editor. 2003. Climate change: an Australian guide to the science and potential impacts. Australian Greenhouse Office, Canberra, Australia.

Powell, W. W., and P. J. DiMaggio. 1991. The new institutionalism in organisational analysis. University of Chicago Press, Chicago, Illinois, USA.

Rutherford, M. 1994. Institutions in economics: the old and the new institutionalism. Cambridge University Press, Cambridge, UK.

Scott, W. R. 1995. Institutions and organizations. Sage Publications, Thousand Oaks, California, USA. http://dx.doi. org/10.1108/01437730310505902

Vatn, A. 2005. Institutions and the environment. Edward Elgar Publishing, Cheltenham, UK.

Vatn A. 2008. Sustainability: the need for institutional change. Pages 61-91 in P. Utting and J. Clapp, editors. Corporate accountability and sustainable development. Oxford University Press, New Delhi, India.

Vatn, A. 2009a. Cooperative behavior and institutions. Journal of Socio-Economics 38:188-196. 
Vatn, A. 2009b. Sustainability, institutions and behavior. Pages 293-314 in V. Beckmann and M. Padmanab, editors. Institutions and Sustainability. Springer, Berlin, Germany.

Vatn, A. 2011. Environmental governance-a conceptualisation. Pages 131-152 in D. Kjosavik and P. Vedeld, editors. The Political Economy of Environment and Development in a Globalized World. Tapir Academic Press, Trondheim, Norway. http://dx.doi.org/10.1093/acprof:oso/97801996562$\underline{02.003 .0002}$

Vedeld, P. 1994. Interdisciplinarity and environment: neoclassical economical and ecological approaches to the use of natural resources. Ecological Economics 10:1-13. http://dx. doi.org/10.1016/0921-8009(94)90031-0

Vedeld, P., and E. Krogh. 2005. Crafting interdisciplinarity in an M.Sc. programme in management of natural resources and sustainable agriculture. The Forestry Chronicle 8(3):330-336.

Watson, C. E. P., S. Migot Adholla, J. Revold, J. Karuga Kihiu, V. Broch Due, P. Gikonyo, E. Bjordal, and J. Okubu. 1985. Lake Turkana fisheries development project. Evaluation Report 5.85. Norwegian Agency for Development Cooperation, Oslo, Norway.

Young, O. R. 1982. Resource regimes: natural resources and social institutions. University of California Press, Berkeley, California, USA.

Young, O. R. 2002. The institutional dimension of environmental change: fit, interplay, and scale. MIT Press, Cambridge, Massachusetts, USA.

Young O. R. 2003. Environmental governance: the role of institutions in causing and confronting environmental problems. International Environmental Agreements: Politics, Law and Economics 3:377-393. http://dx.doi.org/10.1023/B: INEA.0000005802.86439.39

Young, O. R. 2008. Institutions and environmental change: the scientific legacy of a decade of IDGEC research. Pages 345 in O. R. Young, L. A. King, and H. Schroeder, editors. Institutions and environmental change: principal findings, applications, and research frontiers. MIT Press, Cambridge, Massachusetts, USA.

Young, O. R., L. A. King, and H. Schroeder, editors. 2008. Institutions and environmental change: principal findings, applications, and research frontiers. MIT Press, Cambridge, Massachusetts, USA.

Young, O. R., and A. Underdal. 1997. Institutional dimensions of global change. IHDP Scoping Report. International Human Dimensions Programme on Global Environmental Change, Bonn, Germany.

${ }^{[1]}$ Young (2008) distinguishes between resource regimes and environmental regimes-where the first concerns regimes for resources such as fish and forests and the latter concerns pollution issues. The distinction is not important for our discussion, and we will use "resource regime' to cover both issues.

${ }^{[2]}$ Or "foot and shoe", as alluded to by Folke et al. (2007).

${ }^{[3]}$ Paavola et al. (2009) emphasize that in political science, the issue of fit concerns the relations between a new policy intervention and the existing institutional context. Young, however, is working within a systems-oriented perspective where emphasis is at the fit between institutions and the biophysical system. It should be noted, however, that in Young and Underdal (1997) fit between both institutions and the biophysical system and fit between the institutions themselves are emphasized. We take it that Young over time has chosen to link the concept exclusively to the former relation. 